\section{Commentary: All roads lead to} Rome: General surgery still a noble path to cardiothoracic surgery

\author{
Jonathan R. Zurcher, MD, and
}

Kendra J. Grubb, MD, MHA, FACC

The need for cardiac and thoracic surgeons has never been greater in this country, with an estimated 650,000 people succumbing to cardiovascular disease yearly, accruing more than 200 billion dollars in health care costs annually. ${ }^{1}$ The elderly cohort of the population is increasing, and as the current active workforce ages and retires, there is a growing shortage of trained cardiothoracic surgeons to care for these patients. ${ }^{2,3}$

The problem was identified in the early 2000s, as there was a concurrent underfulfillment of cardiothoracic surgery (CTS) fellowship positions by general surgery applicants. One solution to attract intelligent and driven individuals was to create an integrated training pathway, recruiting medical students to complete a 6-year residency (I-6) combining general surgery and CTS training. To that end, the I-6 program has been a success, as the pathway remains highly competitive, with all positions filled annually by a talented and accomplished application pool. ${ }^{4,5}$ It has been suggested this paradigm represents the future of CTS training, as the field grows increasingly complex and more subspecialized, requiring longer training to become proficient. Over the past decade, although the total number of CTS training programs has remained stable, the number of traditional training programs has significantly decreased whereas the number of integrated programs has reciprocally increased. ${ }^{5}$ Moreover, many have postulated the caliber of general surgery residents applying to CTS fellowship has

\footnotetext{
From the Division of Cardiothoracic Surgery, Emory University, Atlanta, Ga. Disclosures: The authors reported no conflicts of interest.

The Journal policy requires editors and reviewers to disclose conflicts of interest and to decline handling or reviewing manuscripts for which they may have a conflict of interest. The editors and reviewers of this article have no conflicts of interest.

Received for publication Sept 14, 2021; revisions received Sept 14, 2021; accepted for publication Sept 15, 2021; available ahead of print Sept 20, 2021.

Address for reprints: Kendra J. Grubb, MD, MHA, FACC, Division of Cardiovascular Surgery, Structural Heart and Valve Center, Emory University School of Medicine, 550 Peachtree St NE, Davis-Fischer, Atlanta, GA 30308 (E-mail: kjgrubb@emory. edu).

J Thorac Cardiovasc Surg 2023;165:1751-2

$0022-5223 / \$ 36.00$

Copyright (c) 2021 by The American Association for Thoracic Surgery

https://doi.org/10.1016/j.jtcvs.2021.09.028
}



$$
\begin{aligned}
& \text { CENTRAL MESSAGE } \\
& \text { General surgery-trained appli- } \\
& \text { cants to cardiothoracic surgery } \\
& \text { remain academically accom- } \\
& \text { plished-still the best and } \\
& \text { brightest. }
\end{aligned}
$$

declined, and we are no longer recruiting the best and brightest.

In this issue of the Journal, Deboever and colleagues ${ }^{6}$ clarify this important nuance of CTS training. Using data from the application pool at the authors' institution for the past 5 years, they demonstrate the continued strength of general surgery residents as they applied for traditional CTS training positions. ${ }^{6}$ The applicants have remained very academically productive, with stable high standardized test scores. There are some limitations worth mentioning. Namely, the authors only reviewed the academic accomplishments and number of letter of recommendations. There was no investigation of the numerous other qualities that make an accomplished and capable cardiothoracic surgeon: grit, resilience, leadership, and interprofessional and interpersonal skills, to name a few. This limitation is not unique to this paper or to program directors across the country, as these are difficult characteristics to determine, quantify, and compare. Furthermore, there is a natural maturation that occurs during the 5 years of general surgery training that cannot be denied.

This work serves as an important reminder that qualified and ambitious applicants interested in pursuing a career in CTS continue to come from general surgery training. As the number of traditional training programs decrease, we would be remiss, as a field, to neglect or disregard this group of applicants. The field of CTS needs to continue to attract a diverse group of bright individuals, both as medical students and surgical residents. 


\section{References}

1. Centers for Disease Control and Prevention. Underlying Cause of Death, 19992019. CDC WONDER Online Database. Atlanta, GA: Centers for Disease Control and Prevention; 2019. Accessed September 1, 2021. Available at: https://wonder. cdc.gov/ucd-icd10.html

2. Grover A, Gorman K, Dall TM, Jonas R, Lytle B, Shemin R, et al. Shortage of cardiothoracic surgeons is likely by 2020. Circulation. 2009;120:488-94.

3. Moffatt-Bruce S, Crestanello J, Way DP, Williams TE Jr. Providing cardiothoracic services in 2035: signs of trouble ahead. J Thorac Cardiovasc Surg. 2018;155: 824-9.
4. Tchantchaleishvili V, Barrus B, Knight PA, Jones CE, Watson TJ, Hicks GL. Six-year integrated cardiothoracic surgery residency applicants: characteristics, expectations, and concerns. J Thorac Cardiovasc Surg. 2013;146:753-8.

5. Bui J, Bennett WC, Long J, Strassle PD, Haithcock B. Recent trends in cardiothoracic surgery training: data from the national resident matching program. J Surg Educ. 2021;78:672-8

6. Deboever N, Bayley E, Vaporciyan A, Antonoff M. Traits. Traits of the current traditional pathway cardiothoracic surgery training pool: results of a cross-sectional study. J Thorac Cardiovasc Surg. 2023;165:1743-50.
See Article page 1743 .

Commentary: Characteristics of traditional pathway applicants may be stable, but for how long?

\author{
Peter D. Drevets, MD, ${ }^{\mathrm{a}}$ and \\ Richard Lee, MD, JD, MBA ${ }^{\mathrm{b}}$
}

Cardiothoracic surgery training pathways have changed over the past 20 years. The introduction of the I-6 programs in conjunction with the traditional 2- or 3-year pathway, generally completed following a general surgery residency, has resulted in 2 distinct groups of trainees. Existing study data largely involve the I-6 trainees. In this edition of the Journal, Deboever and colleagues ${ }^{1}$ attempt to identify trends in traditional-pathway applicants.

The authors' study analyzes characteristics of traditionalpathway applicants from 2015 to 2020. Data are sourced from applications received at the authors' institution, a well-known training program. The authors' institution received a total of 572 applications over the study period, which accounted for $72 \%$ of all applicants over the study time. General scholarly activity including number of publications and presentations were examined, as well as USMLE (United States Medical Licensing Examination)

From the ${ }^{\mathrm{a}}$ Department of Surgery, and ${ }^{\mathrm{b}}$ Division of Cardiothoracic Surgery, Medical College of Georgia, Augusta University, Augusta, Ga.

Disclosures: The authors reported no conflicts of interest.

The Journal policy requires editors and reviewers to disclose conflicts of interest and to decline handling or reviewing manuscripts for which they may have a conflict of interest. The editors and reviewers of this article have no conflicts of interest.

Received for publication Sept 13, 2021; revisions received Sept 13, 2021; accepted for publication Sept 15, 2021; available ahead of print Sept 20, 2021.

Address for reprints: Richard Lee, MD, JD, MBA, Division of Cardiothoracic Surgery, Augusta University, 1120 15th St, BA-4300, Augusta, GA 30912 (E-mail: ricklee@augusta.edu).

J Thorac Cardiovasc Surg 2023;165:1752-3

$0022-5223 / \$ 36.00$

Copyright $₫ 2021$ Published by Elsevier Inc. on behalf of The American Association for Thoracic Surgery

https://doi.org/10.1016/j.jtcvs.2021.09.025

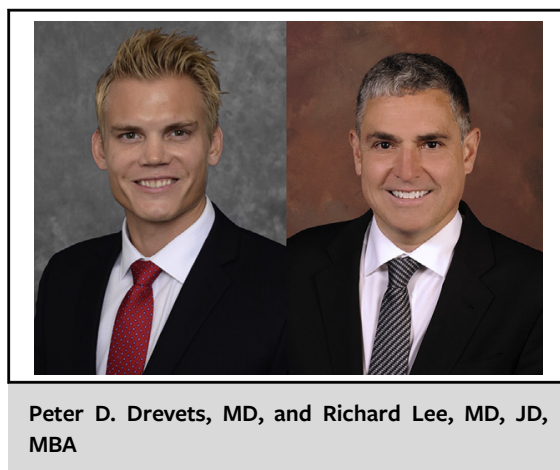

CENTRAL MESSAGE

Characteristics of applicants to

the authors' home institution

traditional-track training pro-

gram have remained largely un-

changed over the 5-year study

period. This will likely change.

and American Board of Surgery Inservice Training Examination scores. The authors concluded that the characteristics of the applicants have largely remained unchanged, with a significant increase seen in USMLE examination scores.

The question the authors attempt to answer is indeed an interesting one. However, the limitations of the study make hard conclusions difficult. The applications received by the authors' institution account for $72 \%$ of total applicants, a reasonable sample size, but is this representative of the total applicant body? There may be underlying nuances in the type of applicants attracted to the authors' institution. USMLE step one scores have increased steadily for all-takers from 2010 to 2020, perhaps diluting the significance seen in a reciprocal increase in traditional-pathway applicants. It is unfortunate that data regarding the 